\title{
Interaction of BSA protein with copper evaluated by electrochemical impedance spectroscopy and quartz crystal microbalance
}

\author{
Edilson M. Pinto $^{\mathrm{a}, \mathrm{b}}$, David M. Soares ${ }^{\mathrm{b}}$, Christopher M.A. Brett ${ }^{\mathrm{a}, *}$ \\ a Departamento de Química, Faculdade de Ciências e Tecnologia, Universidade de Coimbra, 3004-535 Coimbra, Portugal \\ ${ }^{\mathrm{b}}$ Instituto de Física Gleb Wataghin, Unicamp, CP 6165 Campinas SP, Brazil \\ Received 1 August 2007; received in revised form 25 January 2008; accepted 31 January 2008
}

\begin{abstract}
The interaction of bovine serum albumin (BSA) protein with copper in phosphate buffer solution has been studied by a combination of electrochemical impedance spectroscopy (EIS) close to the open circuit potential, with simultaneous monitoring by the electrochemical quartz crystal microbalance (EQCM), in order to throw light on BSA adsorption. Copper films were electroplated onto gold quartz crystals and mounted in the EQCM. Experiments were conducted in the presence and absence of dissolved oxygen and of BSA and the results show the influence of $\mathrm{O}_{2}$ on the protein/metal interaction and also show specific interactions between BSA and copper. The good reproducibility obtained in these experiments suggests future application to other systems and which should lead to a better understanding of the use of such types of protein as corrosion inhibitors.
\end{abstract}

(C) 2008 Elsevier Ltd. All rights reserved.

Keywords: Electrochemical quartz crystal microbalance; Electrochemical impedance spectroscopy; Bovine serum albumin; Copper

\section{Introduction}

As a model protein, bovine serum albumin (BSA) has been employed in a number of research studies concerning the adsorption on and interaction of proteins with different electrode materials. A number of papers have reported the application of the electrochemical QCM (EQCM), usually together with voltammetry, electrochemical impedance spectroscopy (EIS) or surface analysis techniques [1-8].

The development and application of the quartz crystal microbalance (QCM) has grown in many fields of science, and recently new materials such as diamond-like carbon films, polymeric films and nanostructured films have been investigated [9-11]. The QCM has also been used in thin-film deposition monitors and in gas sorption and vapour sensors using carefully selected coating materials as the chemically active interface $[12,13]$. Within a certain range, the resonant frequency shift, $\Delta f_{\mathrm{q}}$, is sufficiently linear with the added loading mass, $\Delta m$, to be independent of the film's other properties as a material, and the

\footnotetext{
* Corresponding author. Tel.: +351 239 835295; fax: +351 239835295 .

E-mail address: brett@ci.uc.pt (C.M.A. Brett).
}

sensitivity, $\Delta f_{\mathrm{q}} / \Delta m$, is proportional to $f_{\mathrm{q}}^{2}$ [14]. In cases where the thin film coating serves simultaneously as an electrode, this proportionality can be useful for correlating charge transfer and mass transfer occurring at electrode-solution interfaces.

EQCM studies have been carried out together simultaneously with double-layer capacitance measurements to investigate the adsorption of BSA on gold [1]. The adsorption of insulin on platinum was studied by simultaneous cyclic voltammetry and EQCM measurements and by EIS [2]. The adsorption of BSA on gold and platinum was probed by simultaneous EIS and QCM measurements in Britton-Robinson buffer with the ferri/ferrocyanide couple as redox probe [3]; it was found that BSA adsorption successfully inhibits gold corrosion during the oxidation of hexacyanoferrate (II). In a different type of investigation, the surfaces of gold electrodes, covered with selfassembled monolayers of PEGylated thiols to prevent adsorption of proteins, were monitored by EIS and QCM measurements, and this approach was found to be wholly successful for resisting BSA adsorption [4]. The influence of BSA on titanium oxide passivation phenomena has been demonstrated [5], and its adsorption on an iron-chromium alloy in acid solution [6] and on passivated chromium $[7,8]$ have very recently been investigated. For passivated chromium $[7,8]$, in situ flow-cell EQCM 
measurements and ex situ XPS measurements were both used and the influence of potential and $\mathrm{pH}$ on the adsorption process were evaluated. Recently, EIS and cyclic voltammetry were utilized to analyse the contamination of samples of BSA by tiny amounts of other proteins [15].

A number of investigations have specifically focused on the interactions of BSA with copper; these studies being helpful for understanding biological phenomena related to covalent copper adduct formation and its role in copper transport [16,17]. A QCM was used in reference [18] to study $\mathrm{Cu}^{2+}$-induced precipitation of BSA onto a gold-coated piezoelectric crystal, and in reference [19] the adsorption of BSA on a gold piezoelectrode coated with sub-monolayer $\mathrm{Cu}$ gave evidence of interaction between BSA and the $\mathrm{Cu}$ atoms on the gold surface. A QCM was also used to monitor the mechanism of interaction between metal ions and BSA, including copper, via adsorption of the metal ions onto a BSA-modified membrane attached to the piezoelectric crystal [20].

Copper has an extremely complex phase diagram [21]. Its electrodeposition and dissolution/corrosion have been studied in acid solution containing chlorides on a gold piezoelectrode EQCM by simultaneous cyclic voltammetry [22,23]. The properties of semiconducting oxides formed on bulk copper have been investigated in alkaline borax solutions using EIS, photocurrent spectroscopy and ellipsometry [24].

In a recent paper, the influence of ultrasound from a horn probe on the adsorption of BSA on bulk copper electrodes at potentials close to open circuit was studied using EIS before, during and after irradiation, with a view to investigating how BSA influenced the formation of surface copper oxide [25]. It was found that the composition of the re-formed copper oxide after irradiation could differ from that before ultrasound, depending on the applied potential, as had been seen previously with other metals [26], and that BSA adsorption hindered oxide formation.

The objective of this work was to show how EIS combined with QCM monitoring of interfacial changes can help in understanding processes occurring at metal-solution interfaces related to adsorption and specific metal-protein interactions, using electrodeposited copper-coated gold piezoelectrodes and BSA as a model system. This is different from ac electrogravimetry experiments, in which simultaneously obtained EQCM and EIS data lead to electrogravimetric and admittance transfer functions, allowing the separation of processes occurring on different timescales by changing the frequency of the potential perturbation [27-29]. AC electrogravimetry was applied most recently to distinguish between different ion insertion/ extraction reactions in Prussian Blue hexacyanoferrate structures [30].

In the experiments carried out here, BSA was allowed to adsorb on the surface of copper which had been previously electroplated onto gold piezoelectric crystals mounted in an electrochemical quartz crystal microbalance (EQCM). It was found to be possible to monitor the frequency of the copper-electroplated piezoelectric quartz crystal during the EIS measurements without influencing the recording of the impedance data. This opens up exciting new possibilities for the obtaining of new information and examining any interfacial alterations during the carrying out of impedance experiments in a "stationary state".

\section{Experimental}

\subsection{Reagents and solutions}

A stock solution of $1 \mathrm{~g} \mathrm{~L}^{-1}$ BSA in $0.1 \mathrm{M}$ phosphate buffer solution $\mathrm{pH} 7.0$ was prepared from sodium dihydrogenphosphate and disodium hydrogenphosphate (Riedel-de-Haën, Germany). A solution prepared from copper sulphate and $98 \%$ sulphuric acid (Merck, Germany) was used for the preparation of electrochemically deposited copper films on the gold piezoelectric crystals, electrochemical voltammetric and impedance experiments were performed in a glass cell containing $40 \mathrm{~mL}$ of solution. Millipore Milli-Q nanopure water (resistivity $>18 \mathrm{M} \Omega \mathrm{cm}$ ) was used in the preparation of all solutions. Experiments were performed at room temperature, $25 \pm 1{ }^{\circ} \mathrm{C}$, in the presence and absence of $\mathrm{O}_{2}$.

Dissolved oxygen was removed from electrolyte solutions, when required, by bubbling ultra-pure nitrogen for at least $10 \mathrm{~min}$ before the experiments were conducted.

\subsection{Electrodes and instrumentation}

AT-cut quartz crystals, frequency $6 \mathrm{MHz}$ (KVG, Germany), plated on both sides with gold were mounted in a home-made EQCM cell, connected to an oscillator circuit and a Hewlett Packard 53131A Universal Counter (Hewlett Packard/Agilent Technologies, USA). The gold-plated area of the crystal exposed to solution was used as the working electrode, area $0.28 \mathrm{~cm}^{2}$. Thin copper films of $\sim 80 \mathrm{~nm}$ thickness and mass of $\sim 221 \mu \mathrm{g}$ were electroplated onto the gold piezoelectric crystal by applying a constant cathodic current of $-1 \mathrm{~mA}$ during $815 \mathrm{~s}$ in deoxygenated electrolyte containing $0.3 \mathrm{M} \mathrm{CuSO}_{4}+2.2 \mathrm{M}$ $\mathrm{H}_{2} \mathrm{SO}_{4}$ using a PAR 273A potentiostat (Princeton Applied Research, USA).

The electrochemical cell also contained a Pt foil counter electrode of area $1 \mathrm{~cm}^{2}$ and a saturated calomel electrode (SCE) as reference.

For electrochemical impedance experiments, the coppercoated gold QCM electrode was linked to a Solartron 1250 Frequency Response Analyser coupled to a Solartron 1286 Electrochemical Interface (Solartron Analytical, UK), controlled by ZPlot 2.4 software (Scribner Associates, USA). A sinusoidal perturbation of $10 \mathrm{mV}$ rms was applied over the frequency range $65.5 \mathrm{kHz}-0.1 \mathrm{~Hz}$, in 10 steps per decade with $60 \mathrm{~s}$ auto-integration at the chosen potentials of $+68,+108$ and $+148 \mathrm{mV}$ versus SCE. During these experiments, the frequency of the coated piezoelectric crystal was monitored by the Hewlett Packard 53131A Universal Counter connected to a PC, using home-made software. The frequencies and potentials were recorded from ca. $20 \mathrm{~s}$ after immersion of the EQCM in solution, as soon as stabilisation of the QCM frequency, which changed due to the different viscosities of air and liquid and to other physicochemical alterations at or near the surface, occurred. 

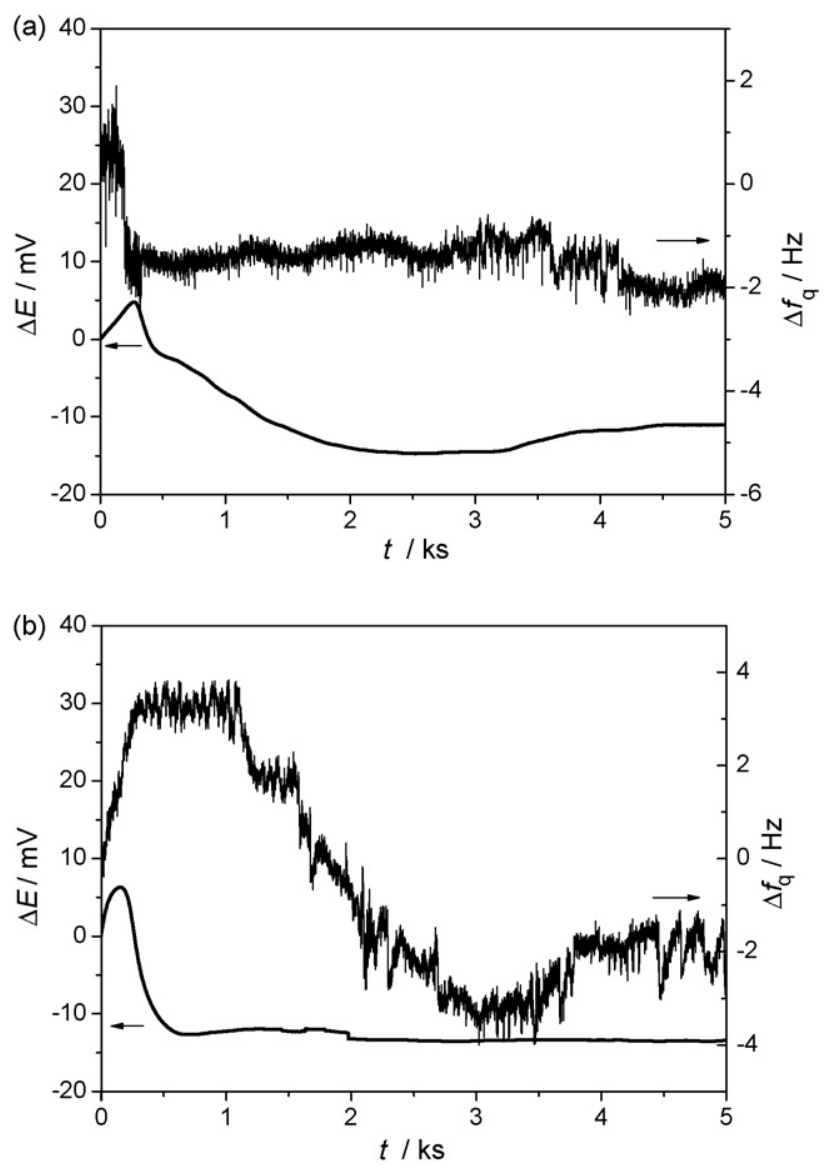

Fig. 1. Variation of open circuit potential, with respect to the initial value on immersion, and frequency with time for electroplated copper QCM electrode in $\mathrm{pH}$ 7.0, 0.1 M phosphate buffer solution (a) without and (b) with $1 \mathrm{~g} \mathrm{~L}^{-1}$ BSA.

\section{Results and discussion}

Experiments were carried out in the presence and absence of $\mathrm{O}_{2}$ and of BSA protein and at various applied potentials defined with respect to the steady-state open circuit potential (OCP) of the system. A value of the OCP of $+0.108 \mathrm{~V}$ versus SCE, for the electroplated copper quartz crystal electrode in $0.1 \mathrm{M}$ phosphate buffer $\mathrm{pH} 7.0$, was obtained at steady state.

\subsection{Open circuit potential and QCM response}

Fig. 1 shows that a relatively steady-state value of open circuit potential was reached after a period of approximately $15 \mathrm{~min}$ immersion in the absence and presence of BSA, after which changes were slow and of the order of a few millivolts. This figure also shows the variation of EQCM frequency with time.

In Fig. 1a, the OCP value increases by $5 \mathrm{mV}$ and then decreases abruptly to $-2 \mathrm{mV}$ at $0.3 \mathrm{ks}$, then slowly decreases to $-15 \mathrm{mV}$ at $2 \mathrm{ks}$ when it becomes relatively stable, only a small potential increase being observed over the next $2 \mathrm{ks}$ until the final value of $+0.108 \mathrm{~V}$ versus SCE is reached. The initial increase of potential at the electroplated copper electrode is probably due to oxidation of copper with formation of oxide. The decrease in potential that follows can be attributed to a mixture of active copper corrosion and formation of $\mathrm{CuO} / \mathrm{Cu}_{2} \mathrm{O}$ species [21,24]. The frequency variation supports this assumption, but the total change, of only $3 \mathrm{~Hz}$, shows that the amount of oxide formed is small and can be calculated to be of the order of $\sim 4$ copper oxide monolayers.

In the presence of BSA in solution, Fig. 1b, there were fewer variations in the open circuit potential and it reached a steady state more quickly after about $0.5 \mathrm{ks}$; although, the initial increase followed by a decrease are still seen. This difference can probably be ascribed to the surface being less accessible to the formation of oxide, owing to blocking by BSA. The frequency change is rather different than in Fig. 1a. At short immersion time, there is a frequency increase of $\sim 3 \mathrm{~Hz}$, the frequency then remaining constant until $1 \mathrm{ks}$, when there is a decrease of $7 \mathrm{~Hz}$ until about $3 \mathrm{ks}$, after which the change in frequency is again small. This suggests that initially the BSA protein interacts with the surface impeding the formation of oxide and promoting a small amount of copper corrosion, which is then followed by adsorption of species, possibly BSA protein, as well as slower oxide formation. An approximate estimate of the possible amount of BSA adsorbed can be made, ignoring any viscoelastic or density changes. The mass of a monolayer of BSA is equal to $54 \mathrm{ng}$, assuming a sectional area of a BSA molecule of around $4 \mathrm{~nm} \times 14 \mathrm{~nm}$, so that $5 \times 10^{11}$ BSA molecules (molecular mass of $66 \mathrm{kDa}[31]$ ), can cover the electrode surface. In this way, the observed frequency change would correspond to about 0.4 protein monolayers, which indicates that the surface directly in contact with the electrolyte would be partly protein and partly copper oxide.

\subsection{Impedance spectra}

Impedance spectra were recorded at various potentials in phosphate buffer solution close to the OCP: OCP $-40 \mathrm{mV}$, OCP and $\mathrm{OCP}+40 \mathrm{mV}$ under the four conditions mentioned above, i.e. with and without BSA and with and without dissolved oxygen. These results are shown in Figs. 2-4. Spectra are shown

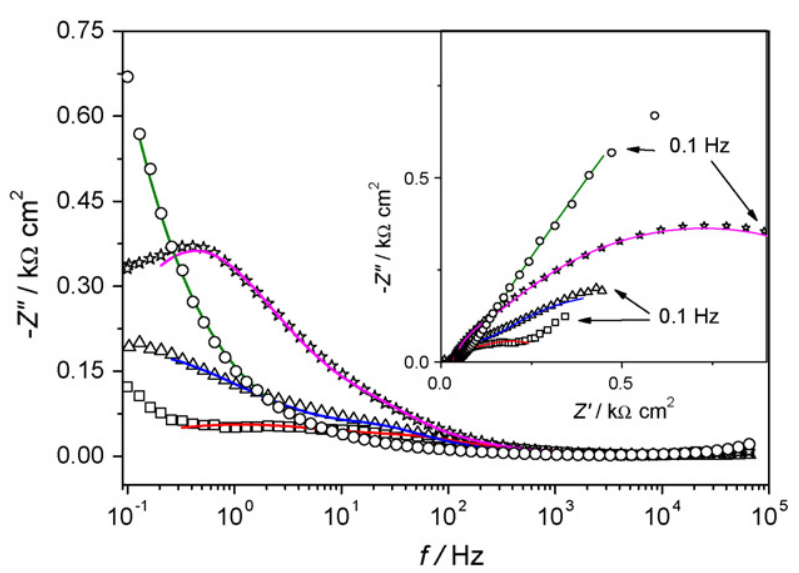

Fig. 2. Plots of $-Z^{\prime \prime}$ vs. $\log f$ and complex plane impedance plots of copper electrode in $0.1 \mathrm{M}$ phosphate buffer solution $\mathrm{pH} 7.0$ at $+68 \mathrm{mV}$ vs. SCE: ( $\square$ )

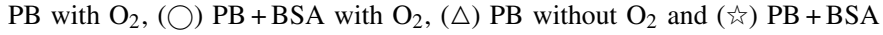
without $\mathrm{O}_{2}$. Lines show fitting to the equivalent circuit in Fig. 5. 


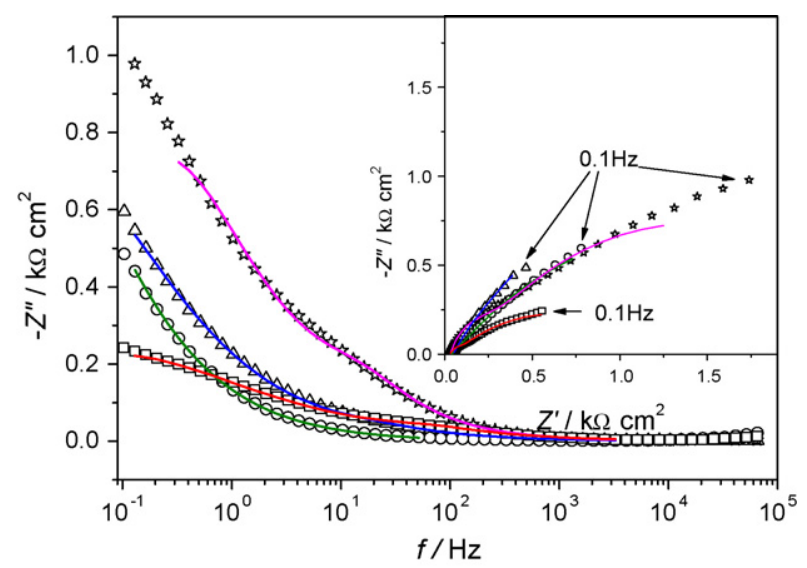

Fig. 3. Plots of $-Z^{\prime \prime}$ vs. $\log f$ and complex plane impedance plots of copper electrode in $0.1 \mathrm{M}$ phosphate buffer solution $\mathrm{pH} 7.0$ at $+108 \mathrm{mV}$ vs. SCE: $(\square)$ $\mathrm{PB}$ with $\mathrm{O}_{2},(\bigcirc) \mathrm{PB}+\mathrm{BSA}$ with $\mathrm{O}_{2},(\triangle) \mathrm{PB}$ without $\mathrm{O}_{2}$ and (ㄴ) $\mathrm{PB}+\mathrm{BSA}$ without $\mathrm{O}_{2}$. Lines show fitting to the equivalent circuit in Fig. 5.

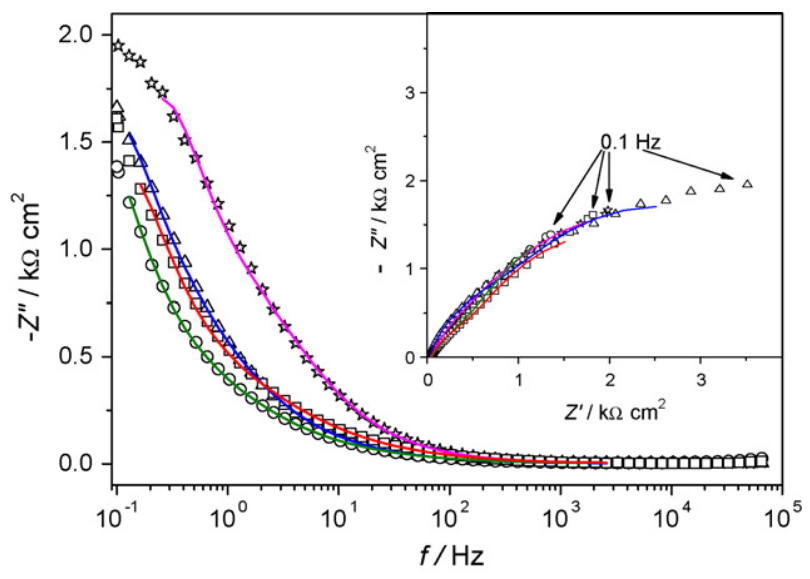

Fig. 4. Plots of $-Z^{\prime \prime}$ vs. $\log f$ and complex plane impedance plots of copper electrode in $0.1 \mathrm{M}$ phosphate buffer solution pH 7.0 at $+148 \mathrm{mV}$ vs. SCE: ( $\square$ ) $\mathrm{PB}$ with $\mathrm{O}_{2},(\bigcirc) \mathrm{PB}+\mathrm{BSA}$ with $\mathrm{O}_{2},(\triangle) \mathrm{PB}$ without $\mathrm{O}_{2}$ and (خ) $\mathrm{PB}+\mathrm{BSA}$ without $\mathrm{O}_{2}$. Lines show fitting to the equivalent circuit in Fig. 5.

both as the imaginary part of the impedance versus logarithm of frequency and as complex plane plots. The former representation can give useful information concerning visualization of the processes occurring as a function of frequency.

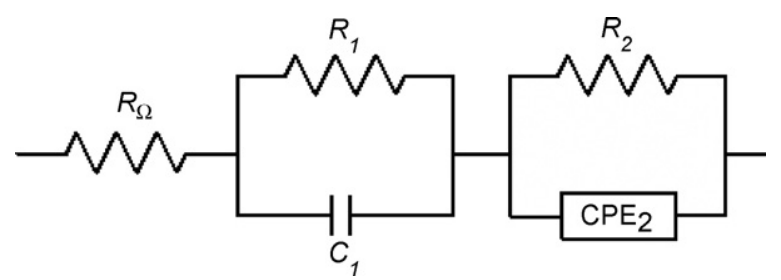

Fig. 5. Equivalent circuit used to model impedance spectra at copper electrodes in phosphate buffer at $+68,+108$ and $+148 \mathrm{mV}$ vs. SCE.

The equivalent circuit used to fit the spectra consists of a parallel $R_{1} C_{1}$ in series with $R_{2} \mathrm{CPE}_{2}$ as shown in Fig. 5. The constant phase element $\mathrm{CPE}=\left\{C(\mathrm{i} \omega)^{n}\right\}^{-1}$ models a non-ideal capacitor in all considered cases. The CPE was found to be necessary because of the heterogeneous nature of the electrode, expressed through the exponent $n$, which was found to be approximately 0.8 , independent of the presence or absence of BSA and probably reflecting the roughness of the polycrystalline surface. This circuit is the same as that used previously in work involving this system [25], except that only one CPE was found to be necessary, which may reflect the different nature of the copper surface, the copper being a thin electroplated film here and pure bulk copper in [25]. In a similar way to reference [25], the $R C$ and $R$ CPE elements of this circuit are taken to represent the copper oxide, together with BSA, film as appropriate and the copper(or copper oxide)-solution interface, respectively. Values of circuit parameters calculated by fitting the spectra presented in Figs. 2-4 (see below) are given in Table 1. The cell resistance $R_{\Omega}$ was around $38 \Omega \mathrm{cm}^{2}$ for experiments in the presence of $\mathrm{O}_{2}$ and $42 \Omega \mathrm{cm}^{2}$ in the experiments carried out in the absence of $\mathrm{O}_{2}$. An equivalent circuit with two parallel $R C$ combinations, corresponding to a surface partly covered by oxide and partly by protein, in series with an $R C P E$ representing the interface with solution was also tested, but without improved fitting.

Fig. 2 shows spectra from all four types of experiment at $+68 \mathrm{mV}$ versus SCE (OCP $-40 \mathrm{mV})$. Differences between the spectra occur principally below $100 \mathrm{~Hz}$, easily seen from the $-Z^{\prime \prime}$ versus $\log f$ plots. In the presence of $\mathrm{O}_{2}$ and without BSA charge transfer occurs and at $1 \mathrm{~Hz}$ it is possible to see the characteristics of another, slower process.

Table 1

Values of resistance and capacitance calculated by fitting of impedance spectra carried out in $0.1 \mathrm{M}$ phosphate buffer solution (PB) in the absence and presence of BSA and $\mathrm{O}_{2}$, shown in Figs. 3-5

\begin{tabular}{|c|c|c|c|c|c|c|c|c|}
\hline \multirow[t]{2}{*}{$E(\mathrm{mV})$ vs. SCE } & \multicolumn{4}{|c|}{ Presence of $\mathrm{O}_{2}$} & \multicolumn{4}{|c|}{ Absence of $\mathrm{O}_{2}$} \\
\hline & $R_{1}\left(\Omega \mathrm{cm}^{2}\right)$ & $C_{1}\left(\mu \mathrm{F} \mathrm{cm}^{-2}\right)$ & $R_{2}\left(\mathrm{k} \Omega \mathrm{cm}^{2}\right)$ & $C_{2}\left(\mathrm{mF} \mathrm{cm}^{-2} \mathrm{~s}^{n-1}\right)$ & $R_{1}\left(\Omega \mathrm{cm}^{2}\right)$ & $C_{1}\left(\mu \mathrm{F} \mathrm{cm}^{-2}\right)$ & $R_{2}\left(\mathrm{k} \Omega \mathrm{cm}^{2}\right)$ & $C_{2}\left(\mathrm{mF} \mathrm{cm}^{-2} \mathrm{~s}^{n-1}\right)$ \\
\hline \multicolumn{9}{|l|}{+68} \\
\hline PB & 21.3 & 130 & 0.31 & 1.55 & 24.4 & 122 & 0.75 & 1.60 \\
\hline $\mathrm{PB}+\mathrm{BSA}$ & 52.6 & 122 & 1.28 & 0.39 & 40.3 & 165 & 0.94 & 1.53 \\
\hline \multicolumn{9}{|l|}{+108} \\
\hline PB & 33.4 & 87 & 1.15 & 1.22 & 24.2 & 325 & 2.96 & 1.79 \\
\hline $\mathrm{PB}+\mathrm{BSA}$ & 163 & 64 & 2.70 & 0.33 & 24.1 & 418 & 2.69 & 1.53 \\
\hline \multicolumn{9}{|l|}{+148} \\
\hline PB & 42.3 & 222 & 5.25 & 0.41 & 33.8 & 149 & 4.12 & 0.61 \\
\hline $\mathrm{PB}+\mathrm{BSA}$ & 244 & 115 & 5.19 & 0.17 & 34.3 & 902 & 4.52 & 0.36 \\
\hline
\end{tabular}


The presence of BSA completely changes the interfacial behaviour, with the second, longer timescale process now not seen in the frequency range studied, and higher impedance values are observed. The film resistance $R_{1}$ increases from $21.3 \Omega \mathrm{cm}^{2}$ in the absence of BSA, to $52.6 \Omega \mathrm{cm}^{2}$ when protein is added and the interfacial resistance, represented by $R_{2}$, from 0.31 to $1.28 \mathrm{k} \Omega \mathrm{cm}^{2}$. The removal of dissolved $\mathrm{O}_{2}$ from the electrolyte leads to BSA having less influence on the impedance values. The largest differences are seen in the effect of BSA on $R_{2}$ where the change is from 0.7 to $0.94 \mathrm{k} \Omega \mathrm{cm}^{2}$ without oxygen instead of from 0.31 to $1.28 \mathrm{k} \Omega \mathrm{cm}^{2}$ in its presence. The associated capacitance values decreased from 1.55 to $0.39 \mathrm{mF} \mathrm{cm}^{-2} \mathrm{~s}^{n-1}$ with dissolved oxygen, but only from 1.60 to $1.53 \mathrm{mF} \mathrm{cm}^{-2} \mathrm{~s}^{n-1}$ without, which may be evidence of a competition between BSA and oxygen for sites on the surface.

At the OCP, $+108 \mathrm{mV}$ versus SCE, Fig. 3, the spectra all exhibit a similar form, with the absence of oxygen and BSA leading to large impedance values. After fitting, analysis shows the very large effect of BSA on the film resistance $R_{1}$ in the presence of oxygen, much more than at $+68 \mathrm{mV}$, and also on $R_{2}$, from 1.15 to $2.70 \mathrm{k} \Omega \mathrm{cm}^{2}$, with lower $C_{1}$ values and a similar reduction in $C_{2}$ as at $+68 \mathrm{mV}$, from 1.22 to $0.33 \mathrm{mF} \mathrm{cm}^{-2} \mathrm{~s}^{n-1}$. In the absence of oxygen, BSA has no influence on $R_{1}$, but increases the film capacitance slightly, as may be expected if there is weak BSA adsorption; the effect of BSA on the interface is small.

These results taken together agree with the expectation that, at this potential, the BSA protein can act as an inhibitor in the presence of dissolved oxygen. Its adsorption on the electrode surface impedes oxide formation increasing the resistance and decreasing the capacitance. However, oxide formation is slower and more difficult in the absence of $\mathrm{O}_{2}$ but the oxide film is more compact and robust, so that the influence of BSA on this process is less.

At $+148 \mathrm{mV}$ versus SCE, Fig. 4 , the tendencies are similar to those at $+108 \mathrm{mV}$ versus SCE. However, the following differences should be noted. First, the values of the oxide film resistance are higher, particularly in the presence of BSA and dissolved oxygen, with much higher associated capacitances $\left(C_{1}\right)$. This suggests that there is a greater contribution from BSA molecules due to strong adsorption. Secondly, the interfacial resistances at $+148 \mathrm{mV}$ are higher both in the presence and absence of oxygen and the charge separation is lower. At this potential, a reasonable amount of copper begins to be oxidised to $\mathrm{Cu}^{2+}$ species, as can also be deduced from the potential-pH diagrams [21], which can then react directly with hydroxide ions, forming a very stable copper oxide film or complexing with BSA (see below).

Rationalisation of the phenomena observed takes into account the fact that the copper surface is covered by a thin oxide film. In borax solution [32], it was observed that this film has a duplex structure, with an outer hydrated copper oxide film and an inner dehydrated film composed of $\mathrm{Cu}_{2} \mathrm{O}$, due to the thermodynamic tendency of $\mathrm{Cu}$ (II) oxide to be reduced to $\mathrm{Cu}(\mathrm{I})$ oxide in the absence of an electric field, with a surface excess of $\mathrm{Cu}$ (II) ions. The same tendency can be expected in phosphate buffer: going to more positive potentials, there is a tendency for more $\mathrm{Cu}^{2+}(\mathrm{aq})$ to be formed and thence easier and faster oxide film formation, particularly as $\mathrm{CuO}$, seen in the increased film resistance values between +68 and $+148 \mathrm{mV}$ versus SCE.

The influence of the interaction of the BSA with copper is greater at more positive potentials in the presence of both BSA and oxygen when more copper ions are formed; additionally, the possibility of BSA binding with two $\mathrm{Cu}(\mathrm{II})$ exists at $\mathrm{pH} 9$ or higher when the protein is in the basic form [16], a situation which may be reached locally at the copper electrode surface. In the absence of oxygen, and because the process is less fast, the oxide film formed is predicted to be thinner and therefore of lower resistance. QCM measurements should be able to aid in understanding these phenomena further.

\subsection{QCM behaviour during recording of impedance spectra}

Preliminary experiments in several electrolyte solutions, with and without the oscillator circuit switched on, showed it to be possible to monitor the frequency of the copper-electroplated piezoelectric quartz crystal during EIS measurements without influencing the spectra. Thus, QCM measurements were carried out in $0.1 \mathrm{M}$ PB solutions, $\mathrm{pH} 7.0$, in the presence and absence of $\mathrm{O}_{2}$, as well as of BSA protein by themselves and during the recording of impedance spectra. The aim was to probe any alterations in adsorption during these experiments. In the analysis of the frequency changes below, any changes in viscoelastic properties and density following protein addition were not considered since the frequency change observed was small and spectra were recorded only after adsorption and frequency stabilisation.

Some examples of the values of the frequency change, $\Delta f_{\mathrm{q}}$, that were recorded are shown in Fig. 6a-e. Fig. 6a shows $\Delta f_{\mathrm{q}}$ as a function of time obtained in experiments in PB solution at $+68 \mathrm{mV}$ versus SCE. No significant frequency variation was detected; which suggests that the interfacial characteristics remained essentially unaltered during the experiment: a change in frequency of $2 \mathrm{~Hz}$, as recorded, corresponds to almost one water monolayer.

In Fig. $6 \mathrm{~b}-\mathrm{d}$, are presented $\Delta f_{\mathrm{q}}$ versus time traces for experiments in $\mathrm{PB}$ solution for the other three types of experiment at $+68 \mathrm{mV}$ versus SCE, i.e. in the presence of $1 \mathrm{~g} \mathrm{~L}^{-1} \mathrm{BSA}$, in PB solution without $\mathrm{BSA}$, and $\mathrm{PB}$ solution without $\mathrm{O}_{2}$ in the presence of $1 \mathrm{~g} \mathrm{~L}^{-1}$ BSA. A linear increase of frequency of about $2 \mathrm{~Hz}$ was observed after $420 \mathrm{~s}$, again not regarded as significant.

The frequency variation observed in all these cases can be explained by taking into account that during the experiments the electrode surface is polarized due to the applied potential, as well as by the sinusoidal perturbation, which can lead to a slightly different charge distribution in the interfacial region on the solution side.

However, in the experiments carried out at the more positive potentials, +108 and $+148 \mathrm{mV}$ versus SCE in PB solution, as exemplified in Fig. 6e, it was observed that there was a significant frequency variation in the presence of BSA protein with $\mathrm{O}_{2}$, see Table 2 (under the other conditions only small alterations in frequency were observed). Changes in frequency of around 18 and $15 \mathrm{~Hz}$ at +108 and $+148 \mathrm{mV}$, respectively, are seen. The variation of $18 \mathrm{~Hz}$ corresponds to a mass loss of $\sim 14$ copper 

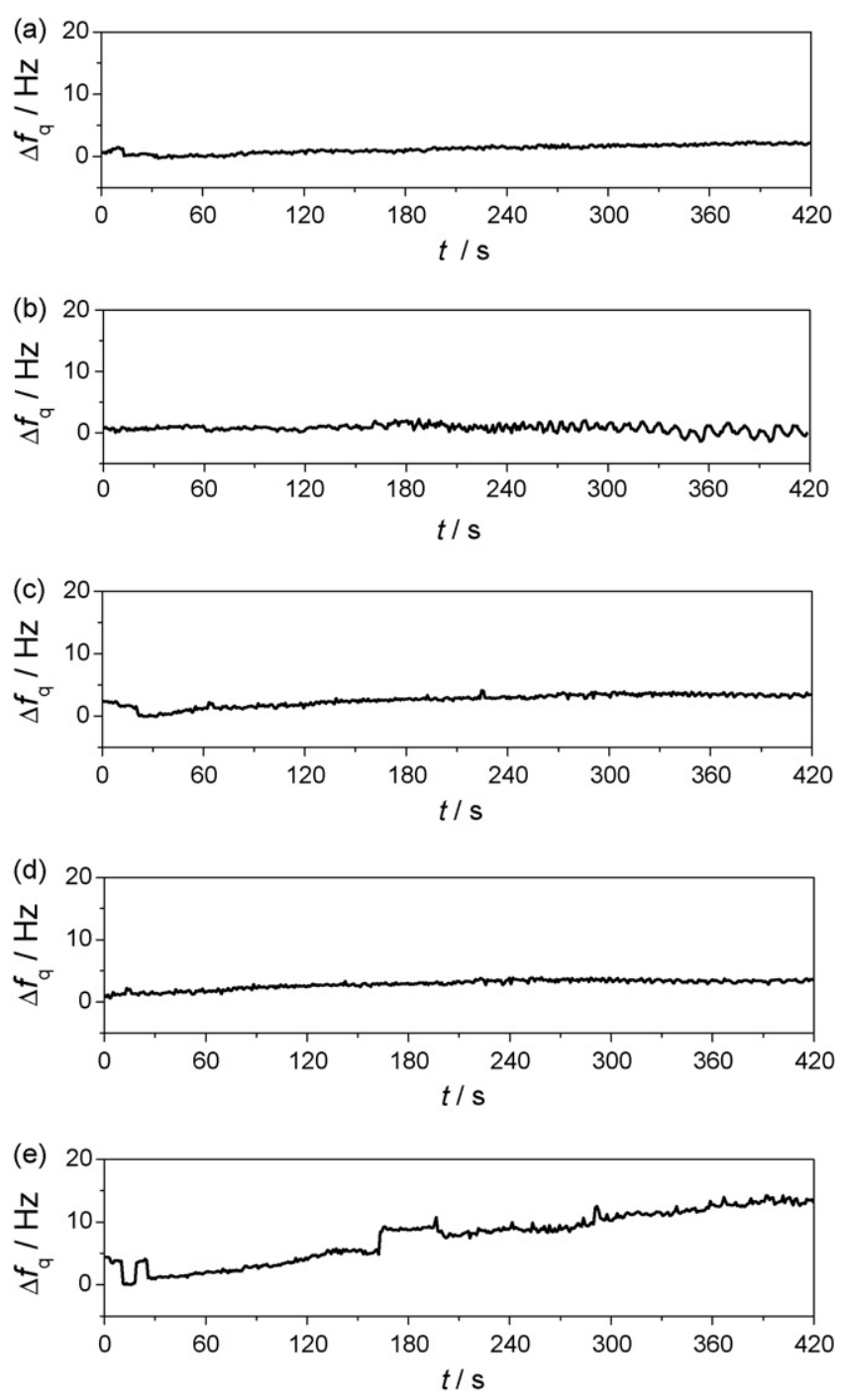

Fig. 6. Frequency variation as function of time, for electroplated copper electrode in $0.1 \mathrm{M}$ phosphate buffer solution $\mathrm{pH} 7.0$ at $+68 \mathrm{mV}$ vs. SCE: in solution of: (a) $\mathrm{PB}$, (b) $\mathrm{PB}+1 \mathrm{~g} \mathrm{~L}^{-1} \mathrm{BSA}$, (c) $\mathrm{PB}$ without $\mathrm{O}_{2}$, (d) $\mathrm{PB}+\mathrm{BSA}$ without $\mathrm{O}_{2}$ and (e) at $+108 \mathrm{mV}$ vs. SCE in PB solution with $1 \mathrm{~g} \mathrm{~L}^{-1} \mathrm{BSA}$.

Table 2

Values of frequency change, $\Delta f_{\mathrm{q}}$, obtained from the QCM, monitored during EIS experiments, in $0.1 \mathrm{M}$ phosphate buffer solution (PB) in the absence and presence of $\mathrm{O}_{2}$ and $1 \mathrm{~g} \mathrm{~L}^{-1}$ BSA protein, see Fig. 6

\begin{tabular}{lll}
\hline$E(\mathrm{mV})$ vs. SCE & $\Delta f_{\mathrm{q}}(\mathrm{Hz})$ & \\
\cline { 2 - 3 } & Presence of $\mathrm{O}_{2}$ & Absence of $\mathrm{O}_{2}$ \\
\hline+68 & 2 & 2 \\
PB & 2 & 2 \\
PB + BSA & & \\
+108 & 4 & 4 \\
PB & 18 & 5 \\
PB + BSA & & \\
+148 & 2 & 5 \\
PB & 15 & 5 \\
PB + BSA & & \\
\hline
\end{tabular}

Frequency accuracy $\pm 1 \mathrm{~Hz}$. monolayers. This surface corrosion, which hinders the reaching of the steady-state condition of the surface observed in the other cases, is unexpected, since EIS suggests that protein adsorption would lead to corrosion inhibition. Since in the absence of $\mathrm{O}_{2}$ such a frequency variation was not detected, it suggests that the phenomenon is both $\mathrm{O}_{2}$ - and potential-dependent.

These results, taken together with the analysis of the impedance spectra in the previous section, suggest that BSA interacts with the copper ions formed to a greater extent in the presence of dissolved oxygen and at more positive potentials. The fact that there is a net mass loss suggests that some of these complexes are lost to solution. The higher film resistance observed by EIS shows that this "dissolution" process is slow, also by the fact that the mass loss observed takes place over a period of $7 \mathrm{~min}$. Recording further spectra, together with QCM monitoring, lead to exactly the same positive frequency change as obtained previously. In reference [1], the frequency and double-layer capacitance changes were used to elucidate the kinetics of BSA adsorption on gold electrodes and a mass increase due to adsorption was found. Here in this study on copper electrodes, monitoring of the frequency changes was done after adsorption has taken place, since the immersion solution already contains BSA, significant changes corresponding to mass loss only being evident at the more positive potentials tested where there are specific interactions between BSA and copper ions.

These measurements show the important potentialities, for the correct interpretation of experimental data, of measuring the QCM response at the same electrode where impedance spectra are being recorded.

\section{Conclusions}

Adsorption of the protein BSA, studied as model protein, on copper and oxidised copper surfaces and its interaction with copper ions to form copper-BSA complexes has been studied by electrochemical impedance and by the quartz crystal microbalance. The influence of BSA protein depends on the presence or absence of oxygen and on the applied potential, which determines the amount of copper ions released from the surface. The greatest effect is found to be at the more positive potential and in the presence of dissolved oxygen, where there is a mass loss but at the same time the resistance of the copper oxide film is highest, with strong adsorption of BSA as well as the formation of BSA complexes with copper ions, which can be lost to solution. Further characterisation of the adsorption process and degree of adsorption using the quartz crystal nanobalance with coppercoated quartz crystals will be carried out in the future. This study augurs well for application to other systems in the future and a better understanding of the mode of action of proteins as corrosion inhibitors.

\section{Acknowledgements}

The authors acknowledge financial support from EU-Alfa project PETRA II (ALFA_II-0343-FA-FCD-FI), from Fundação para a Ciência e Tecnologia (FCT), Portugal for a Ph.D. 
grant (SFRH/BD/31483/2006) for E.M.P., from ICEMS/FCT, Research Unit 103, Coimbra-Portugal and Instituto de Física Gleb Wataghin, Campinas-Brazil.

\section{References}

[1] F. Lacour, R. Torresi, C. Gabrielli, A. Caprani, J. Electrochem. Soc. 139 (1992) 1619

[2] J.E.I. Wright, N.P. Cosman, K. Fatih, S. Omanovic, S.G. Roscoe, J. Electroanal. Chem. 564 (2004) 185.

[3] Q. Xie, C. Xiang, Y. Yuan, Y. Zhang, L. Nie, S. Yao, J. Coll. Inter. Sci. 262 (2003) 167.

[4] B. Menz, R. Knerr, A. Göpferich, C. Steinem, Biomaterials 26 (2005) 4237.

[5] X.L. Cheng, S.G. Roscoe, Biomaterials 26 (2005) 7350.

[6] I. Frateur, L. Lartundo-Rojas, C. Methivier, A. Galtayries, P. Marcus, Electrochim. Acta 51 (2006) 1550.

[7] I. Frateur, J. Lecoeur, S. Zanna, C.-O.A. Olsson, D. Landolt, P. Marcus, Electrochim. Acta 52 (2007) 7660.

[8] A. Ithurbide, I. Frateur, A. Galtayries, P. Marcus, Electrochim. Acta 53 (2007) 1336.

[9] J. Moon, S. Park, Y. Lee, G.S. Bang, J. Electroanal. Chem. 464 (1999) 230.

[10] H.J. Zeng, Y. Jiang, G.Z. Xie, J.S. Yu, Sens. Actuator B Chem. 122 (2007) 1.

[11] T.W. Chao, C.J. Liu, A.H. Hsiech, H.M. Chang, Y.S. Huang, D.S. Tsai, Sens. Actuator B Chem. 122 (2007) 95.

[12] W.H. King, Anal. Chem. 36 (1964) 1735.

[13] C.K. O’Sullivan, G.G. Guilbault, Biosens. Bioelectron. 14 (1999) 663.

[14] G. Sauerbrey, Z. Phys. 155 (1959) 206.
[15] M.F. Smiechowski, V.F. Lvovich, S. Roy, A. Fleischman, W.H. Fissell, A.T. Riga, Biosens. Bioelectron. 22 (2006) 670.

[16] Y. Zhang, D.E. Wilcox, J. Biol. Inorg. Chem. 7 (2002) 327.

[17] R.A. Løvstad, BioMetals 17 (2004) 111.

[18] Y. Cai, Q. Xie, A. Zhou, Y. Zhang, S. Yao, J. Biochem. Biophys. Methods 47 (2001) 209.

[19] M. Hepel, M. Stobiecka, Bioelectrochemistry 70 (2007) 155.

[20] C. Mizuno, S. Bao, T. Hinoue, T. Nomura, Anal. Sci. 21 (2005) 281.

[21] E. Protopopoff, P. Marcus, Electrochim. Acta 51 (2005) 408.

[22] D. Giménez-Romero, C. Gabrielli, J.J. Garcia-Jareño, H. Perrot, F. Vicente, J. Electrochem. Soc. 153 (2006) 332.

[23] S. Kologo, M. Eyraud, L. Bonou, F. Vacandio, Y. Massiani, Electrochim. Acta 52 (2007) 3105.

[24] J.O. Zerbino, L.M. Gassa, J. Solid State Electrochem. 7 (2003) 177.

[25] E.M. Pinto, D.M. Soares, C.M.A. Brett, J. Appl. Electrochem. 37 (2007) 1367.

[26] N.L.P.A. Morais, C.M.A. Brett, J. Appl. Electrochem. 32 (2002) 653.

[27] S. Bourkane, C. Gabrielli, M. Keddam, Electrochim. Acta 34 (1989) 1081.

[28] S. Cordoba-Torresi, C. Gabrielli, M. Keddam, H. Takenouti, R. Torresi, J. Electroanal. Chem. 290 (1990) 261.

[29] S. Bourkane, C. Gabrielli, F. Huet, M. Keddam, Electrochim. Acta 38 (1993) 1023.

[30] D. Giménez-Romero, P.R. Bueno, C. Gabrielli, J.J. García-Jareño, H. Perrot, F. Vicente, J. Phys. Chem. B 110 (2006) 19352.

[31] S.H. Jung, S.J. Choi, H.J. Kim, T.W. Monn, Biosci. Biotechnol. Biochem. 70 (2006) 2064.

[32] J.O. Zerbino, M.F.L. de Mele, J. Appl. Electrochem. 27 (1997) 335. 